\title{
Molecular characterisation of type 1 Gaucher disease families and patients: intrafamilial heterogeneity at the clinical level
}

\author{
O Amaral, A M Fortuna, L Lacerda, R Pinto, M C Sa Miranda
}

\begin{abstract}
Type 1 Gaucher disease families were studied in an attempt to establish a phenotype/genotype correlation in affected persons and also to identify carriers accurately. In the Portuguese type 1 Gaucher patients, screening for mutations N370S, L444P, R463C, and $1066+1$ $G \rightarrow A$ allowed the identification of $85 \%$ of the alleles among unrelated patients. A subclinical case with genotype N370S/ $1066+1 \mathrm{G} \rightarrow \mathrm{A}$ was identified in one family in which there were three other symptomatic sibs. To our knowledge this is the first subclinical case with a genotype

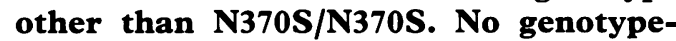
phenotype correlation could be established and considerable clinical heterogeneity was found even among sibs with the same genotype. The data collected on the origins of the Gaucher families indicated two areas in northern Portugal where a higher frequency of the disease may be expected to exist.
\end{abstract}

( Med Genet 1994;31:401-404)

Gaucher disease (GD) is the most prevalent lysosomal storage disorder. This autosomal recessive disease is caused by the defective catabolism of glucosylceramide usually owing to a deficiency of glucocerebrosidase (EC 3.2.1.45). Clinically, three major types can be distinguished on the basis of the presence and extent of neurological involvement. The most common form of GD is the heterogeneous non-neuronopathic type $1,{ }^{1}$ which is particularly frequent among Ashkenazi Jews. ${ }^{2}$

In Portugal, type 1 is also the most frequent form of GD. In a previous work we reported that in the Portuguese patients mutation N370S was the most common, accounting for about $60 \%$ of the Gaucher alleles. ${ }^{3}$ Our results contrast with reports on other GD patients of non-Jewish ancestry; studies on Canadian, ${ }^{4}$ British, ${ }^{5}$ and Italian ${ }^{6}$ patients showed that this mutation accounted for approximately $40 \%$ of the mutant alleles in type 1 patients. The main aim of the present work was to characterise GD families, attempting to establish a correlation between the patients' genotype and their clinical phenotype and to identify the carriers accurately. Information about the origins of the families was also collected in an attempt to trace the families as far back as possible and determine the geographical origins of the GD alleles in Portugal.

\section{Materials and methods PATIENTS AND RELATIVES}

A total of 23 type 1 Gaucher disease patients and 95 blood relatives from 11 of the 17 Gaucher families were studied. All the people studied were white and of Catholic ancestry. No relationship could be detected between the different families.

Patients were subjected to clinical and analytical examination. They all presented low glucocerebrosidase activity in leucocytes. The clinical examinations were performed by the same physician (AMF), therefore assuring little variability in the clinical evaluation, and the degree of clinical severity established was based on previously proposed parameters. ${ }^{7}$ All patients were free of neurological complications.

\section{SAMPLE PREPARATION}

Genomic DNA (gDNA) of patients and close relatives was isolated from white blood cells by standard methods ${ }^{8}$ with minor modifications. Buccal wash samples, which proved to be very convenient to obtain, were used in the study of relatives. The buccal wash consisted of a sterile saline solution. PCR amplification was carried out using either $500 \mathrm{ng}$ of gDNA or $10 \mu \mathrm{l}$ of the cellular extract. The reactions were carried out in a total volume of $100 \mu \mathrm{l}$.

\section{MUTATION ANALYSIS}

The DNA of most patients and some relatives was initially studied by dot blot analysis of PCR products with ASO probes for the most common mutations. ${ }^{3}$ Patients with unidentified alleles were screened for a total of 19 mutations $^{9-23}$ by specific restriction endonuclease digestion ${ }^{910}$ of PCR amplified products.

The screening for recombinant alleles in patients with mutation L444P was also carried out by specific restriction enzyme digestion, using StyI and HphI, which allow the identification of pseudogene sequences at genomic nucleotides 5957 and 6306, respectively. Genomic nucleotide numbering is according to the sequence published by Horowitz et al. ${ }^{24}$

In the characterisation of the families, relatives were screened for the mutations identified in the index cases.

\section{Results}

Of all the mutations tested in the patients, only four were encountered, namely N370S, L444P

\author{
Received 23 July 1993 \\ for publication \\ 22 November 1993 \\ M C Sa Miranda \\ Correspondence to
}




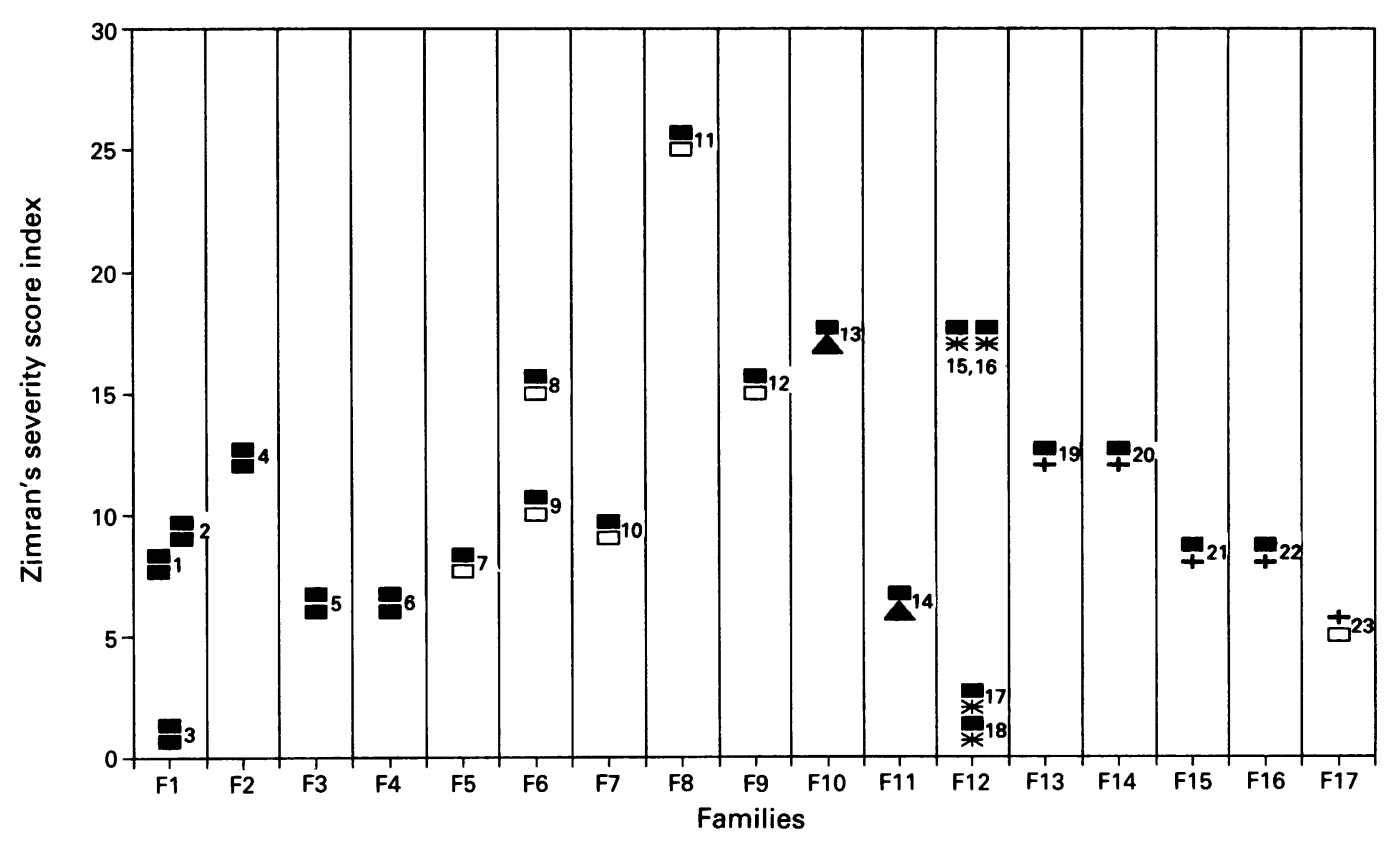

\section{:N370S/N370S; :N370S/R463C; :N370S/L444P; \\ :N370S/1066+1G->A; $:$ :N370S/?; 古:L444P/?}

Genotype and clinical severity scores of type 1 GD patients. Patients within families are all sibs. Severity scores calculated according to Zimran et al. ${ }^{7}$

(including pseudogene recombinant alleles), $\mathrm{R} 463 \mathrm{C}$, and $1066+1 \mathrm{G} \rightarrow \mathrm{A}$, allowing the identification of $85 \%$ of the alleles among unrelated patients.

Clinically, the patients' phenotypes ranged from subclinical to severe, with no apparent correlation with the genotype at the glucocerebrosidase locus, as shown in the figure. Intrafamilial variability in the severity of symptoms, shown in the table, was particularly evident in two families (F1 and F12). Family 1 was one of N370S homozygotes where, at the time of the study of two affected sisters, a subclinical adult male was identified. In family 12 , there were two moderately affected sisters (P15 and P16), both with early onset, and an additional patient was diagnosed during her third pregnancy when haematological problems arose. In this same family, a subclinical case (aged 28) was picked up at the time of this study. All four patients presented the same genotype (N370S/1066 + $1 \mathrm{G} \rightarrow \mathrm{A})$. Additional clinical heterogeneity was verified in family 6 , where P8 and P9 (both N370S/L444P) presented diverse clinical histories. Patient 8 , four years younger than her affected brother, had earlier onset than him followed by massive hepatosplenomegaly and lung involvement. The older brother, P9, who was only identified while his sister was being studied, was found to present milder hepatosplenomegaly, radiographic signs of bone involvement, and delayed growth.

Of the six patients in the N370S/L444P group, two (P11 and P12) were found to have pseudogene recombinant alleles. The presence of recombinant alleles could not be related to the degree of severity of the illness, although one patient died of liver disease (P11) and the other one is a moderately affected woman in

Clinical and analytical characteristics of patients from three unrelated families

\begin{tabular}{|c|c|c|c|c|c|c|c|}
\hline \multirow[b]{2}{*}{ Family } & \multirow[b]{2}{*}{ Patient } & \multicolumn{6}{|c|}{ Clinical and analytical characteristics* } \\
\hline & & Onset $(y)$ & Cytopenia & Splenomegaly & Hepatomegaly & Bone involvement & Other organ involvement $\dagger$ \\
\hline F1 & P1 & 7 & + & + & + & ++ & - \\
\hline $\begin{array}{l}\mathrm{F} 1 \\
\mathrm{~F} 1\end{array}$ & P2 & 20 & - & - & - & + & + \\
\hline $\begin{array}{l}\text { F1 } \\
\text { F6 }\end{array}$ & P3t & 29 & - & - & - & - & - \\
\hline $\begin{array}{l}\text { F6 } \\
\text { F6 }\end{array}$ & P8 & 3 & + & +++ & +++ & - & + \\
\hline $\begin{array}{l}\text { F6 } \\
\text { F12 }\end{array}$ & P9 & 6 & - & ++ & ++ & ++ & - \\
\hline F12 & P15 & 3 & + & $\mathbf{s}$ & ++ & +++ & $\overline{-}$ \\
\hline F12 & P16 & 12 & + & $\mathbf{s}$ & ++ & ++ & + \\
\hline F12 & P17 & 32 & + & - & - & - & - \\
\hline F12 & P18† & 28 & - & - & - & - & - \\
\hline
\end{tabular}

* - not detectable, + mild, ++ moderate, +++ massive, $s$ splenectomised.

Other organ involvement refers to kidneys and lungs.

† Subclinical cases presenting glucocerebrosidase deficiency in leucocytes. 
her forties (P12). It is worth noting that both patients had been splenectomised. In the case of patients 19 to 23 only one of the alleles was identified by testing all the 19 previously mentioned mutations.

Among the 95 blood relatives examined (including 37 obligate carriers) two subclinical cases and 72 carriers were identified; 55 carried mutation N370S, six carried mutation $1066+1$ $\mathrm{G} \rightarrow \mathrm{A}$, five carried mutation L444P, and six were obligate carriers for undefined mutations. In two of the families examined (F6 and F10) two persons were found to be N370S carriers even though they had not contributed to the patients' genotype. In one case the carrier was a non-consanguineous sister in law and in the other case it was a grandmother who had transmitted the normal allele to the patient's father.

The establishment of parental origins showed that $62.5 \%$ of 32 parents originated from two geographical areas in northern Portugal, which comprise a population of 0.5 million. The remaining $37.5 \%$ were scattered throughout the country (including the Azores islands). No interfamilial relationships were detected; however, detailed genealogy was unavailable earlier than the third generation.

\section{Discussion}

In the Portuguese patients, the proportions of Gaucher alleles were found to differ from those previously described in non-Ashkenazi patients. ${ }^{2}$ Identification of $85 \%$ of the Gaucher alleles among unrelated patients was possible by screening for mutations N370S (59\%), L444P including recombinant alleles $(17.5 \%)$, $\mathrm{R} 463 \mathrm{C}(5 \cdot 9 \%)$, and $1066+1 \mathrm{G} \rightarrow \mathrm{A}(2 \cdot 9 \%)$.

The severity score applied, although useful because it allows the standard comparison of the degree of disease severity, has a major draw-back in that patients with different symptoms may present the same severity score, as happened with P13, P15, and P16 (all with a score of 17).

The results obtained clearly indicate that it is not possible to predict the evolution of the clinical symptoms even among affected sibs. The finding of subclinical cases with allele N370S in the homozygous state or associated with a null allele, such as the $1066+1 \mathrm{G} \rightarrow \mathrm{A}$ allele (in P18), contradicts the hypothesis of this latter genotype being associated with a particularly severe clinical phenotype ${ }^{11}$ and seems to indicate that a correlation between the amount of functional residual glucocerebrosidase and the clinical phenotype cannot be established in Gaucher disease. The remarkable capacities of activation of the N370S mutated glucocerebrosidase when in the presence of saposin $C$ and phosphatidylserine ${ }^{25}$ could partially account for the considerable heterogeneity verified among patients with allele N370S.

On the basis of the N370S carrier frequency in Portugal, ${ }^{26}$ a large number of subclinical homozygotes is expected to exist. The present identification of a subclinical compound heterozygote $(\mathrm{N} 370 \mathrm{~S} / 1066+1 \mathrm{G} \rightarrow \mathrm{A})$ leads us to believe that the number of undiagnosed type 1 patients may be larger than previously thought.

The lack of correlation between the genotype at the glucocerebrosidase locus and the patient's phenotype suggests that additional factors have to be involved in the clinical expression of this disease. The identification of these factors seems to be essential for the better understanding of the pathophysiology of GD.

We wish to thank the patients and their relatives for their cooperation as well as the clinicians who referred the patients to us and provided their medical records. This work was supported by grants BD/2299/92-ID and BD/1042/90-ID from ported by grants

1 Barranger J, Ginns E. Glucosylceramide lipidoses: Gaucher disease. In: Scriver CS, et al, eds. The metabolic basis of disease. In: Scriver CS, et al, eds. The metabolic basis of
inherited disease. New York: McGraw-Hill, 1989:1677inherit

2 Beutler E. Gaucher disease: new molecular approaches to diagnosis and treatment. Science 1992;256:794-9.

3 Amaral O, Lacerda L, Santos R, Pinto RA, Aerts H, Sa Miranda MC. Type 1 Gaucher disease: molecular, biochemical, and clinical characterization of patients from northern Portugal. Biochem Med Metab Biol 1993;49:97107.

4 Choy F, Woo M, Der Kaloustian V. Molecular analysis of Gaucher disease: screening of patients in the Montreal Quebec region. Am F Med Genet 1991;41:469-74.

5 Walley A, Barth L, Ellis I, Fensom A, Harris A. Gaucher's disease in the United Kingdom: screening non-Jewish patients for the two common mutations. $f$ Med Genet 1993;30:280-3.

6 Tuteja R, Bembi B, Agosti E, Baralle F. 1448C mutation linked to the Pv1.1-genotype in Italian patients with linked to the Pv1.1-genotype in Italian patients
Gaucher disease. Hum Molec Genet 1993;2:781-4.

7 Zimran A, Gross E, West C, Sorge J, Kubitz M, Beutler E. Prediction of severity of Gaucher's disease by identification of mutations at the DNA level. Lancet 1989;ii:34952.

8 Miller S, Dykes D, Polensky H. A simple salting out procedure for extracting DNA from human nucleated cells. Nucleic Acids Res 1988;16:1215.

9 Beutler E, Gelbart T, Kuhl W, Zimran A, West C. Mutations in Jewish patients with Gaucher disease. Blood 1992;79:1662-6.

10 Beutler E, Gelbart T, West C. Identification of six new Gaucher disease mutations. Genomics 1993;15:203-5.

11 He GS, Grabowski GA. Gaucher disease: a $G+1 \rightarrow A+1$ IVS2 splice donor site mutation causing exon 2 skipping in the acid $\beta$-glucosidase mRNA. Am $尹$ Hum Genet in the acid $\beta$-glucc

12 Beutler E, Gelbart T, Kuhl W, Sorge J, West C. Identification of the second common Jewish Gaucher disease mutation makes possible population based screening for the heterozygote state. Proc Natl Acad Sci USA 1991;88: 10544-7.

13 Graves PN, Grabowski GA, Eisner R, Palese P, Smith FI. Gaucher disease type 1: cloning and characterization of a cDNA encoding acid $\beta$-glucosidase from an Ashkenazi Jewish patient. DNA 1988;7:521-7.

14 Eyal N, Firon N, Wilder S, Kolodny EH, Horowitz M. Three unique base pair changes in a family with Gaucher disease. Hum Genet 1991;87:328-32.

15 Latham TE, Theophilus BDM, Grabowski GA, Smith FI. Heterogeneity of mutations in the acid $\beta$-glucosidase gene of Gaucher disease patients. DNA Cell Biol 1991;10:1521 .

16 Beutler E, Gelbart T. Gaucher disease associated with a unique KpnI restriction site: identification of the aminounique KpnI restriction site: identification of the amino

17 Eyal N, Wilder S, Horowitz M. Prevalent and rare mutations among Gaucher patients. Gene 1990;96:277-83.

18 Tsuji S, Martin BM, Barranger JA, Stubblefield BK, LaMarca ME, Ginns EI. Genetic heterogeneity in type 1 Gaucher disease: multiple genotypes in Ashkenazic and non-Ashkenazic individuals. Proc Natl Acad Sci USA 1988;85:2349-52.

19 Beutler E, Gelbart T, West C. The facile detection of the nt 1226 mutation of glucocerebrosidase by 'mismatched' PCR. Clin Chim Acta 1990;194:161-6.

20 Theophilus BDM, Latham T, Grabowski GA, Smith FI. Comparison of RNase A, chemical cleavage, and GCclamped denaturing gradient gel electrophoresis for the detection of mutations in exon 9 of the detection of mutations in exon 9 of the human acid

21 glucosidase gene. Nucleic Acids Res 1989;17:7707-22. of mutations in Gaucher patients by cDNA cloning. $A m \mathcal{F}$ Hum Genet 1989;44:365-77.

22 Tsuji S, Choudary PV, Martin GM, et al. A mutation in the human glucocerebrosidase gene in neuronopathic human glucocerebrosidase gene in neuron
Gaucher disease. $N$ Engl f Med 1987;316:570-5. 
23 Hong CM, Ohashi T, Yu XJ, Weiler S, Barranger JA. Sequence of two alleles responsible for Gaucher disease. DNA Cell Biol 1990;9:233-41.

24 Horowitz M, Wilder S, Horowitz Z, Reiner O, Gelbart T, Whe gene and pseu25 Sa Miranda MC, Aerts J, Pinto R, et al. Activity of glucocerebrosidase in extracts of different cell types from type 1 Gaucher disease patients. Clin Genet 1990;38:21827.

26 Lacerda L, Amaral O, Pinto R, Oliveira P, Aerts J, Sa Miranda MC. Gaucher disease: $5841 \mathrm{G}$ glucocerebrosidase gene frequency in the Portuguese, a non Ashkenazi Jewish population. Clin Genet (submitted). 